\title{
CONSENSUS REPORT ON THE PREVENTION, DIAGNOSIS, AND TREATMENT OF CERVICAL CANCER - A PERSPECTIVE FROM THE IMMUNE SYSTEM TOWARD IMMUNOTHERAPY
}

\section{PREFACE}

According to GLOBOCAN 2018 data ${ }^{1}$, cervical cancer (CC) is the fourth most common cancer in women worldwide and the third most frequent cancer in Mexican women. In recent years, incidence and mortality rates have been declining worldwide at a rate of $1.6 \%$ per year ${ }^{2}$. This decline has resulted from the increased access to health-care services and successful screening programs. However, more than $80 \%$ of cases and $88 \%$ of deaths occur in low- and middleincome countries ${ }^{3,4}$. There is a strong inverse correlation between the level of development of the country and the incidence and mortality from CC. Survival once the $\mathrm{CC}$ has been diagnosed is also much better in developed than in developing countries ${ }^{5}$.

The natural history of CC has been widely studied, and persistent infection with high-risk types of human papillomavirus (HPV) has been established as a fundamental etiology in the development of the tumor ${ }^{6}$. $\mathrm{HPV}$ is a common sexually transmitted infection, and it usually occurs soon after the initiation of sexual activity. Most infections with HPV clear spontaneously, but infection with high-risk HPV (particularly the 16 and 18 types) may progress to cervical lesions and eventually to CC. HPV 16 and 18 are responsible for $70 \%$ of CC cases worldwide ${ }^{7}$. However, the majority of HPV infections is resolved spontaneously because of the immune response against HPV.

The immune system plays a significant role in the prevention of HPV infection, the development of cervical lesions and, ultimately, tumor progression. When an individual is infected with HPV, optimal humoral and cellular immune responses are required to clear the infection ${ }^{8}$. If the immune system is not functioning optimally, a chronic HPV infection leads to progression of cervical lesions and eventually to CC. The humoral immune response involves the production of neutralizing antibodies, which prevent viral particles to infect cervical epithelial cells. This is the mechanism behind the protective effect of HPV vaccines. Vaccines that prevent infection with high-risk types of HPV have been a major breakthrough for CC prevention. Monovalent, bivalent, quadrivalent, and nonavalent vaccines have been tested in placebo-controlled clinical trials and proven to be safe, immunogenic, and efficient at preventing infection; however, these have been just recently implemented in Mexico and other developing countries, and it will take several years before we can observe an impact on the incidence of CC.

Considering that, an optimal immune response is necessary at each step throughout the natural history of the disease, from the clearance of HPV infection to immune response against the tumor, the role that nutrition plays in the immune system cannot be overlooked. Epidemiologically, CC affects mostly women from low- and middle-income countries, where protein-energy malnutrition is also prevalent ${ }^{9}$. Malnutrition constitutes the main cause of mild immunodeficiency and, in conjunction with micronutrient deficiencies, may blunt an adequate immune 
Table 1. Classification guide for quality of evidence and strength of recommendations ${ }^{10}$

\begin{tabular}{c} 
Quality of evidence \\
\hline High \\
Moderate \\
Low \\
Very low \\
\hline Strength of recommendation \\
Strong in favor of intervention \\
Weak in favor of intervention \\
Weak against intervention \\
Strong against intervention
\end{tabular}

response against HPV, allowing the establishment of chronic infection and the consequent development of CC. Dietary patterns have been studied for their role on the immune response, as they can either promote a pro-inflammatory or anti-inflammatory state. It is important to establish recommendations for an adequate nutritional intervention that may help contribute to an optimal immune capacity to respond against the tumor and modulate inflammation, while providing the elements to establish a healthy gut microbiota, which plays a role in the training of the immune system and may contribute to the tumor microenvironment.

A consensus meeting of experts was recently organized in Mexico with the purpose of analyzing and summarizing the immunological aspects of $C C$, based on the most recent scientific evidence. A multidisciplinary group of professionals was selected based on clinical expertise and scientific trajectory. Each participant was issued an e-mail invitation, and those who accepted were called to attend the meeting at the State of Mexico, Mexico, on May 2019. The panel included oncologists (surgeons, gynecologists, and radio-oncologists), nutritionists, biologists, and immunologists from different Mexican institutions. The organizer of this meeting was the program MICAELA (Modelo Integral de atención del CÁncer cErvicouterino Localmente avanzado y Avanzado - integral model for the attention of locally advanced and advanced CC, Mexico) with support from the Instituto Nacional de Cancerología (Mexican National Cancer
Institute). Participants from other public and government institutions were also involved in this consensus meeting.

According to their expertise, participants were divided into several subgroups, and each subgroup was assigned to review and analyze the available scientific information about particular issues on prevention, diagnosis, and treatment of CC. After analysis and discussion within each subgroup, GRADE scores and comments emerged, and the level of evidence and strength of recommendations were established, according to Table $1^{10}$. From resulting analyses, the corresponding manuscripts were prepared as in-depth reviews and submitted to peer review by the journal before publication.

We envision that these reviews may lead to proposals for an improved screening and support to patients with CC. Moreover, we expect that clinical trials are developed to strengthen the evidence for immunotherapy-based treatment as well as nutritional interventions for CC patients.

The Guest Editors are indebted to the MICAELA program for its academic support; to each expert for their willingness to participate in the consensus; to Productos Roche S.A. de C.V., Merck Sharp and Dohme Comercializadora S. de R.L. de C.V., and ABBOTT Laboratories S.A. de C.V., Mexico, for their financial support; and to all patients who inspired us to organize the consensus. 


\section{REFERENCES}

1. Bray F, Ferlay J, Soerjomataram I, Siegel RL, Torre LA, Jemal A. Global cancer statistics 2018: GLOBOCAN estimates of incidence and mortality worldwide for 36 cancers in 185 countries. CA Cancer J Clin. 2018:68:394-424.

2. Forouzanfar MH, Foreman KJ, Delossantos AM, Lozano R, Lopez $A D$, Murray CJL, et al. Breast and cervical cancer in 187 countries between 1980 and 2010: a systematic analysis. Lancet. 2011:378:1461-84

3. Randall TC, Ghebre R. Challenges in prevention and care delivery for women with cervical cancer in Sub-Saharan Africa. Front Oncol. 2016;6:1-7.

4. Chabra S. Cervical cancer preventable, treatable, but continues to kill women. Gynecol Obstet. 2017;S4:1-2.

5. Small W, Bacon MA, Bajaj A, Chuang LT, Fisher BJ, Harkenrider MM, et al. Cervical cancer: a global health crisis. Cancer. 2017; 123:2404-12.
6. Walboomers JM, Jacobs MV, Manos MM, Bosch FX, Kummer $\mathrm{JA}$, Shah KV, et al. Human papillomavirus is a necessary cause of invasive cervical cancer worldwide. J Pathol. 1999;189: 12-9.

7. Herrero R, Castle PE, Schiffman M, Bratti MC, Hildesheim A, Morales J, et al. Epidemiologic profile of type -specific human papillomavirus infection and cervical neoplasia in Guanacaste, Costa Rica. J Infect Dis. 2005;191:1796-807.

8. Emeny RT, Wheeler CM, Jansen KU, Hunt WC, Fu TM, Smith $\mathrm{JF}$, et al. Priming of human papillomavirus Type 11-specific humoral and cellular immune responses in college-aged women with a virus-like particle vaccine. J Virol. 2002;76: 7832-42.

9. Aswathy S, Reshma J, Avani D. Epidemiology of cervical cancer with special focus on India. Int J Womens Health. 2015;7:405.

10. Oñate-Ocaña LF, Ochoa-Carrillo FJ. Sistema GRADE para clasificar nivel de evidencia y grado de las recomendaciones para la elaboración de guías de buena práctica clínica. Cir Ciruj. 2009;77:417-9.

\section{Lucely Cetina-Pérez ${ }^{1 *}$ and Denisse Castro-Eguiluz ${ }^{1,2}$}

${ }^{1}$ Department of Clinical Research and Medical Oncology, Instituto Nacional de Cancerología, Mexico City; ${ }^{2}$ Consejo Nacional de Ciencia y Tecnología (CONACyT), Mexico City, Mexico

*Corresponding author:

Lucely Cetina Pérez

E-mail: lucelycetina.incan@gmail.com
Received for publication: 31-03-2020

Approved for publication: 16-04-2020

DOI: $10.24875 / R I C .20000129$ 